\title{
LECTURA Y ESCRITURA
}

\section{INTRODUCCIÓN}

La intencionalidad prioritaria de este artículo es la de abrir un puente de comunicación entre los lectores y escritores que de alguna manera gusten de esta temática buscando una mayor solidez en la pertenencia de las ideas que aquí planteo las cuales básicamente oscilan en afirmaciones alrededor de: qué es y qué no es aprender a leer y escribir, qué es y qué no es enseñar a leer y escribir. De la misma manera presento algunas precisiones sobre la importancia de estos procesos (leer y escribir) en el aprendizaje en general y en el desarrollo congnitivo y social de los infantes.

"Se enseña a los niños a trazar letras y hacer palabras con ellas, pero no se les enseña el lenguaje escrito. Se enfatiza tanto la mecánica de leer lo escrito que se eclipsa el lenguaje escrito en cuanto taly.

\section{VIGOTSKY.}

Cuando el niño entra en el maravilloso mundo de la expresión gráfica, los adultos (padres y maestros) son protagonistas en el desarrollo de sus garabateos, ya que de la forma como reciben esta ¿-presión por parte del niño y la atención que estos le pongan depende el éxito en el proceso de aprendizaje.

\author{
José Avtovio Ardilı A. \\ Profesor de Matemáticas en la \\ Universidad Surcolombiana de Neiva
}

Los primeros garabateos se caracterizan porque tienen sentido, varían en longitud y dirección. Es importante resaltar que estos no son un intento de reproducir la realidad y además el niño no está en condiciones de hacer otras tareas que requieran control previo de sus movimientos.

Durante el 5o. ó 6o. año de edad, el niño se comienza a interesar por la escritura, haciendo una imitación de lo que ve hacer a los adultos cuando utilizan el papel y el lápiz.

En un comienzo , el dibujo y la escritura evolucionan en forma paralela. Durante algún tiempo, el hecho de trazar letras es para el niño sinónimo de dibujar y en ésta actividad, es capaz de copiar palabras y frases, antes de adquirir conciencia de lo que éstas representan.

Poco a poco, los dos sistemas simbólicos comienzan a evolucionar separadamente. El dibujo toma carácter convencional simbolizando el objeto, mientras la escritura, también convencional, simboliza el lenguaje. Aquí, el niño descubre que sus dibujos no solo pueden ser objetos conocidos sino también letras.

El niño comienza dibujando la escritura: copia cualquier letra o palabra y más tarde se da cuenta de la existencia de un código, y pide que le hagan un modelo para él reproducirlo. 
Luego copia las palabras en forma global y su reproducción se asemeja, más o menos según el grado de madurez, al dibujo inicial. Para llegar realmente a escribir debe reproducir y respetar todas las exigencias del código. La escritura, a diferencia del dibujo, se compone de signos que deben ser reproducidos exactamente para que no cambien su significado y para que pueda cumplir con su función comunicadora.

La comprensión del lenguaje escrito se realiza en primer lugar, a través del lenguaje hablado, pero poco a poco, éste camino se va abriendo hasta que el lenguaje hablado acaba por desaparecer como vínculo intermedio (escribe o lee en silencio, sin hacer el sonido correspondiente a la L letra). de papel. Con esta actividad están mostrando su creciente interés por el lenguaje escrito, con lo cual ellos podrán aumentar sus posibilidades de comunicación no verbal.

Su gran interés por el mundo social y natural, más allá de la exveriencia inmediata, es una de sus principales características, ante esta situación. padres y familiares han de fomentar el acceso a los textos escritos y a las historias narradas.

"Escribir" no es
trazar penosamente
letras, no es copiar
palabras o frases: es
transmitir mediante
la grafía un mensaje
que sea comprendido
por todos los que
saben hablar y leer la
lengua empleada.

Saber leer tiene gran importancia en la vida del niño. su experiencia en el aprendizaje de la lectura sella el destino de una vez por todas, de su desarrollo congnitivo y social.

Si el proceso hacia el aprendizaje de la lectura ha sido provechoso, todo irá bien, pero cuando no aprende a leer como es debido las consecuencias pueden ser irremediables.

Enseñar a leer es lo más importante de cuanto se le enseña al niño en la escuela, su trascendencia no tiene paralelo. Por eso es tan importante la forma de enseñar a 
leer: de la manera como el niño experimenta el aprendizaje de la lectura determinará su opinión del aprendizaje en general y de su concepto de si mismo como aprendiz e incluso como persona.

Los aspectos técnicos (descifrar palabras o significados), y saber como leer. deberían quedar claramente separados de la introducción del niño a la literatura. El niño desde el principio debe aprender a leer como resultado de su deseo espontáneo de acceder al lenguaje escrito. es decir, de ser capaz de leer libros por sí mismo.

A los niños que adquieren gran interés por la lectura en casa les es fácil leer en la escuela y constituyen la mayoría abrumadora de aquellos que más adelante son buenos lectores.

El saber descifrar un texto no significa que sabe leer. Se necesita comprender el texto. Los textos significativos para el alumno son claves en el proceso de comprensión.

Edmund Huey hace más de 70 años dijo:

"Al niño jamás debería permitírsele leer por el hecho de leer, como proceso formal o fin en sí mismo. La lectura debe hacerse siempre por el interés o el valor intrínseco de lo que se lee y nunca debería hacerse con considerarse como un "ejercicio". Por consiguiente la pronunciación de las palabras será siempre secundaria ante la obtención del significado de frases enteras y esto desde el principio... El aprender a comprender la literatura verdadera debería empezar en casa y en los primeros días de escuela y proseguir sin interrupción".
Jeane S.Chall (1976) afirmó:

"El contenido más adecuado para los niños de primer y segundo grado son las leyendas populares y los cuentos de hadas. Tiene un atractivo universal... Son cuentos que contienen luchas y triunfos, el bien y el mal, risas y lágrimas... temas que han desaparecido de las historias modernas basadas en experiencias conocidas... Los niños al igual que los adultos, disfrutan llorando a moco tendido de vez en cuando. Hacer que todas las historias terminen bien resulta no solo irreal, sino también insípido".

La presencia de ilustraciones (recargadas de información) hace menos interesante la lectura, pues éstas suprimen mucho vocabulario. (El niño puede no darle prelación al texto escrito puesto que, la ilustración le dice mucho sobre él).

Además, nadie ha demostrado aún que los dibujos ayuden al niño a reconocer las palabras o a comprender el texto. Experimentos recientes prueban que las ilustraciones pueden entorpecer los esfuerzos del niño en el intento de edificar una comprensión.

Vale la pena señalar y reflexionar sobre lo que Carlos Alberto Jiménez (1996), nos dice:

"Al ingresar el niño a la escuela se encuentra en una edad en la que los sentimientos, las fantasías dominan el pensamiento; así, pues, cuando algo adquiere verdadera importancia para él como, "aprender a leer y escribir", el niño lo invierte o lo transforma en un proceso mágico o fantástico; de ahí que la visión practicista de la lectura y de la escritura como desciframiento no tiene sentido: él necesita aprender con fantasía. Los 
modelos mecanicistas de las cartillas de lecto-escritura en Colombia favorecen más la reproducción de esquemas que la imaginación, la fantasía y la construcción simbólica".
Es pertinente agregar que para enseñar a leer se debe favorecer más el encuentro con el significado que con el proceso de descifrar o de repetir reglas.

\section{BIBLIOGRAFÍA}

1. BETTELHEIN, B., Zelan, K. (1989). Aprender a leer. Barcelona: Crítica.

2. CASTORINA, J.A. Ferreiro, E., Lerner, D. (1996). Piaget. Vigotsky: Constribuciones para replantear el debate. Buenos Aires: Paidós S.A.

3. JIMÉNEZ, C. A. (1996). La lúdica como experiencia cultural. Santafé de Bogotá: Cooperativa Edit. Magisterio. 